\title{
Sunset transition of negative charge in the D-region ionosphere during high-ionization conditions
}

\author{
P. T. Verronen ${ }^{1}$, Th. Ulich $^{2}$, E. Turunen ${ }^{2}$, and C. J. Rodger ${ }^{3}$ \\ ${ }^{1}$ Finnish Meteorological Institute, Earth Observation, Helsinki, Finland \\ ${ }^{2}$ Sodankylä Geophysical Observatory, University of Oulu, Sodankylä, Finland \\ ${ }^{3}$ Physics Department, University of Otago, Dunedin, New Zealand
}

Received: 20 September 2005 - Revised: 1 December 2005 - Accepted: 21 December 2005 - Published: 7 March 2006

\begin{abstract}
The solar proton event of October 1989 and especially the sunset of 23 October is examined in this study of negative ion chemistry, which combines measurements of nitric oxide, electron density, and cosmic radio noise absorption with ion and neutral chemistry modelling. Model results show that the negative charge transition from electrons to negative ions during sunset occurs at altitudes below $80 \mathrm{~km}$ and is dependent on both ultraviolet and visible solar radiation. The ultraviolet effect is mostly due to rapid changes in atomic oxygen and $\mathrm{O}_{2}\left({ }^{1} \Delta_{g}\right)$, while the decrease in $\mathrm{NO}_{3}^{-}$ photodetachment plays a minor role. The effect driven by visible wavelengths is due to changes in photodissociation of $\mathrm{CO}_{3}^{-}$and the subsequent electron photodetachment from $\mathrm{O}^{-}$, and at higher altitudes is also due to a decrease in the photodetachment of $\mathrm{O}_{2}^{-}$. The relative sizes of the ultraviolet and visible effects vary with altitude, with the visible effects increasing in importance at higher altitudes, and they are also controlled by the nitric oxide concentration. These modelling results are in good agreement with EISCAT incoherent scatter radar and Kilpisjärvi riometer measurements.
\end{abstract}

Keywords. Ionosphere (Ion chemistry and composition; Ionosphere-atmosphere interactions; Particle precipitation)

\section{Introduction}

Negative ions are a feature of the D-region ionosphere, where they hold a substantial portion of the negative charge. Negative ion chemistry is initiated by electron attachment to molecular oxygen

$\mathrm{O}_{2}+\mathrm{e}+\mathrm{M} \rightarrow \mathrm{O}_{2}^{-}+\mathrm{M}$

after which subsequent reactions form other ions, including complex clusters (see, e.g. Hargreaves, 1992, 231-233). Based on laboratory work and in-situ measurements, the main negative ions are expected to be $\mathrm{CO}_{3}^{-}$and $\mathrm{NO}_{3}^{-}$, and

Correspondence to: $\mathrm{P} . \mathrm{T}$. Verronen

(pekka.verronen@fmi.fi) their hydrates. The main reaction path leading from the initial $\mathrm{O}_{2}^{-}$to these "terminal" ions involves neutral ozone, carbon dioxide, and nitric oxide, and the formation of intermediate ion $\mathrm{O}_{3}^{-}$(Reid, 1987). Negative ions are present at altitudes below $80 \mathrm{~km}$, where the atmospheric density is high enough so that the 3-body reaction of Eq. (1) is efficient. The balance with electrons is then determined by electron detachment reactions, such as

$\mathrm{O}_{2}^{-}+\mathrm{O} \rightarrow \mathrm{O}_{3}+$ e.

Most of the balancing reactions depend on the solar light, such that at night the electrons nearly disappear from altitudes below $80 \mathrm{~km}$ and negative charge is held largely by the ions. During sunset, there is a transition of negative charge from electrons to negative ions, and a reverse transition occurs during sunrise. Any realistic modelling of the D-region ionosphere requires consideration of negative ion chemistry.

The transition of negative charge is driven by solar light. Of those ions that are neutralised by photons, only $\mathrm{NO}_{3}^{-}$has such a high electron affinity that ultraviolet (UV) radiation is required (Collis and Rietveld, 1990, and references therein). Other ions, such as $\mathrm{CO}_{3}^{-}$, are also affected by electromagnetic radiation at visible (VIS) wavelengths. Furthermore, indirect solar effects, driven by UV radiation, are also present during transitions, because changes in atomic oxygen and $\mathrm{O}_{2}\left({ }^{1} \Delta_{g}\right)$ affect reactions like the one given in Eq. (2). A transition should therefore display dependence on both UV and VIS light but the relative magnitudes of these effects are expected to vary with altitude and are also controlled by nitric oxide (NO) concentration, which determines the balance between the main ions $\mathrm{NO}_{3}^{-}$and $\mathrm{CO}_{3}^{-}$(Reid, 1987). The remaining uncertainties in the photochemistry of negative ions and the high variability of NO in the auroral regions make modelling of this transition quite challenging, especially because in-situ measurements of negative ion concentrations are rare.

The October 1989 Solar Proton Event (SPE) is one of the largest SPEs ever observed. During an SPE, high-energy protons precipitate into the atmosphere, down to mesospheric and stratospheric altitudes, causing both ionospheric and neutral atmospheric changes (see, e.g. Verronen et al., 2005, 
and references therein for more information on neutral atmospheric effects). Ionization due to SPEs typically has a maximum around the stratopause region (ionospheric C-region), where the quiet-time ionization due to galactic cosmic rays is relatively weak, and covers the magnetic polar cap area more or less uniformly. Earlier work on the October 1989 SPE has addressed both the ionospheric and atmospheric effects. Rietveld and Collis (1993) have studied ionospheric characteristics using Incoherent Scatter (IS) radar spectral measurements, while Reid et al. (1991) and Jackman et al. (1995) have investigated the production of $\mathrm{NO}_{\mathrm{x}}$ (odd nitrogen) and subsequent loss of ozone.

The sunrise/sunset transition effects during this particular SPE have been studied by Collis and Rietveld (1990) and del Pozo et al. (1999). Based on electron density measurements by IS radar, Collis and Rietveld (1990) concluded that at sunrise the electron release from negative ions is due to UV photodetachment. del Pozo et al. (1999) studied the rapid change in IS radar spectral width during sunset and underlined the importance of atomic oxygen in the negative charge balance. On the basis of these studies, it seems that both the changes in solar illumination, as well as the changes in neutral atmospheric constituents must be taken into account when modelling twilight transitions. Typically, ion chemistry models take the neutral atmosphere as a static background and are therefore not well suited for transition studies.

In this paper, we study the sunset transition of 23 October 1989 at a high-latitude location during a solar proton event. Our tool, a coupled ion and neutral chemistry model, has been updated for transition studies and is used to interpret electron density, cosmic radio noise absorption, and nitric oxide measurements. We will show that the model, taking into account the changes in the neutral atmosphere, as well as the changes in the electron photodetachment processes, is able to represent the sunset transition with reasonable success, in agreement with the measurements. The model results are used to discuss the relative importance of different processes contributing to the transition.

\section{Sodankylä Ion Chemistry model}

The Sodankylä Ion Chemistry model (SIC) is a 1-D chemical model designed for ionospheric D-region studies. The model was applied first by Burns et al. (1991) in a study of EISCAT radar data, and thereafter by, for example, Turunen (1993), Rietveld et al. (1996), Ulich et al. (2000), Verronen et al. (2002), and Clilverd et al. (2005). A detailed description of the original SIC model, in which only ion chemistry was considered, can be found in Turunen et al. (1996). The latest version solves time-dependent concentrations of 63 ions, including 29 negative ions, as well as 13 neutral species $\left(\mathrm{O}\left({ }^{3} \mathrm{P}\right)\right.$, $\mathrm{O}\left({ }^{1} \mathrm{D}\right), \mathrm{O}_{3}, \mathrm{~N}\left({ }^{4} \mathrm{~S}\right), \mathrm{N}\left({ }^{2} \mathrm{D}\right), \mathrm{NO}, \mathrm{NO}_{2}, \mathrm{NO}_{3}, \mathrm{HNO}_{3}, \mathrm{~N}_{2} \mathrm{O}_{5}$, $\mathrm{H}, \mathrm{OH}$, and $\mathrm{HO}_{2}$ ) between the altitudes of 20 and $150 \mathrm{~km}$, with a $1-\mathrm{km}$ resolution, taking into account several hundred chemical reactions and external forcing due to solar radiation $(1-422 \mathrm{~nm})$, electron and proton precipitation, and galactic cosmic rays. The model includes molecular and eddy diffusion in the vertical direction. For a recent detailed description of the model, see Verronen et al. (2005) and references therein. Figure 1 presents a diagram of the negative ion reaction paths considered in the SIC model. Note, however, that photodetachment and photodissociation reactions are not shown in the diagram.

For this study, two new neutrals were added as unknowns: $\mathrm{O}_{2}\left({ }^{1} \Delta_{g}\right)$ and $\mathrm{H}_{2} \mathrm{O}_{2}$. Both of these have strong diurnal variation in the stratosphere and lower mesosphere. The chemical scheme was updated accordingly. $\mathrm{O}_{2}\left({ }^{1} \Delta_{g}\right)$ is produced by photodissociation of ozone and is then deactivated in a reaction with molecular oxygen or by quenching (see, e.g. Brasseur and Solomon, 1986). The reaction rate coefficients for the loss reactions were taken from Sander et al. (2003) and Thomas et al. (1983), respectively. Note that the ionic reactions of $\mathrm{O}_{2}\left({ }^{1} \Delta_{g}\right)$ were already included in the model and are given by Turunen et al. (1996). For $\mathrm{H}_{2} \mathrm{O}_{2}$, we added the loss by photodissociation using cross sections from Sander et al. (2003). The other reactions important to $\mathrm{H}_{2} \mathrm{O}_{2}$ were already included in the model.

\subsection{Modelling of the sunset of 23 October 1989}

The modelling started with an initialisation of the model, i.e. the same day (mid-October conditions) was modelled over and over again until a repeatable diurnal cycle was reached. This initialisation then provided the starting concentrations for the SPE modelling, which was run from 18 October, 00:00 UT (about $37 \mathrm{~h}$ before the initial onset of the SPE) until 23 October, 24:00 UT. Ionization rates due to proton precipitation were calculated using proton flux measurements of the GOES-7 satellite as input, in the manner described by Verronen et al. (2005). For the present study, the location of all modelling is that of the EISCAT VHF radar in Troms $\varnothing$, Norway $\left(69.59^{\circ} \mathrm{N}, 19.23^{\circ} \mathrm{E}\right)$. The model was run for a restricted altitude range of $20-120 \mathrm{~km}$ instead of taking the default upper limit at $150 \mathrm{~km}$, and the results were saved with a 5 -min time resolution.

The SPE started in the afternoon (UT) of 19 October 1989. Measured fluxes of high-energy protons peaked during the next day, with the $E>30 \mathrm{MeV}$ proton flux reaching values higher than $10^{8} \mathrm{~m}^{-2} \mathrm{~s}^{-1} \mathrm{sr}^{-1}$, which means an increase by 5 orders of magnitude above the quiet-time values. Subsequent peaks occurred on 23 and 25 October, with the $>30 \mathrm{MeV}$ proton flux values exceeding $10^{7} \mathrm{~m}^{-2} \mathrm{~s}^{-1} \mathrm{sr}^{-1}$. At the D-region altitudes, the calculated ionization rates from the onset of the event until the end of 23 October varied between $10^{8}$ and $10^{10} \mathrm{~m}^{-3} \mathrm{~s}^{-1}$. Thus, the ionization due to the SPE clearly exceeded the quiet-time ionization sources (see, e.g Hargreaves, 1992, p. 230). In the model, we have neglected the ionization by hard X-rays $(0.1-0.8 \mathrm{~nm})$, a highly variable source which can significantly contribute to the Dregion ionization. However, during a strong SPE it is reasonable to assume that the ionization is dominated by the precipitating protons. 


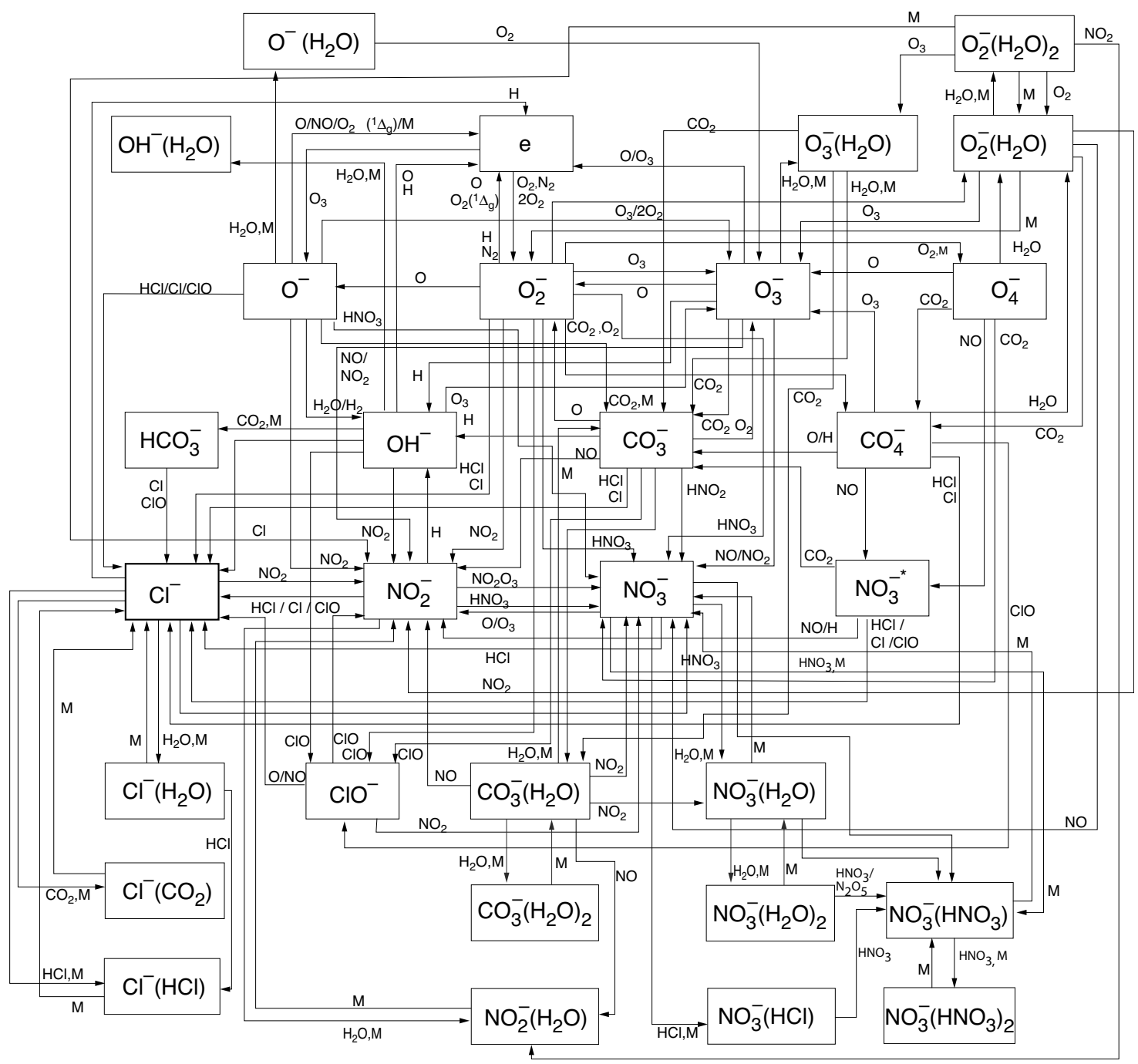

Fig. 1. Block diagram for the negative ion scheme of the SIC model. The various ions in the blocks are either the reactants or the final products of the reactions sketched by the connecting arrows. The arrows are labelled with the neutral constituents taking part in the reactions. Note that photodetachment and photodissociation reactions are not shown.

We are especially interested in the sunset of 23 October because of the EISCAT measurements made between 12:00 and 18:00 UT in a special lower D-region mode. However, it is important to model the whole history of the event before the radar experiment, because changes in the neutral atmosphere caused by the SPE, which can be cumulative and long-lasting, are likely to be important to the sunset transition characteristics. Odd nitrogen $\left(\mathrm{NO}_{\mathrm{x}}=\mathrm{N}+\mathrm{NO}+\mathrm{NO}_{2}\right)$ is produced in significant amounts through dissociation of molecular nitrogen via particle impact and ion chemistry (Rusch et al., 1981). Also odd hydrogen $\left(\mathrm{HO}_{\mathrm{x}}=\mathrm{H}+\mathrm{HO}+\mathrm{HO}_{2}\right)$ is produced, through hydrate ion chemistry following the ionization (Solomon et al., 1981). As already mentioned, NO plays and important part in determination of the ion balance. In addition, enhancements in $\mathrm{NO}_{\mathrm{x}}$ and $\mathrm{HO}_{\mathrm{x}}$ subsequently lead to an ozone decrease through catalytic reactions (see, e.g. Brasseur and Solomon, 1986, p. 291-299). While $\mathrm{NO}_{\mathrm{x}}$ is expected to affect ozone in the upper stratosphere, an $\mathrm{HO}_{\mathrm{x}}$ increase will lead to an ozone depletion at D-region altitudes. Ozone changes have an effect, e.g., on the production of $\mathrm{O}_{3}^{-}$, which is an important intermediate ion for the "terminal" ions $\mathrm{CO}_{3}^{-}$and $\mathrm{NO}_{3}^{-}$. The twilight transition of negative charge will also be affected, because ozone is in a photochemical balance with atomic oxygen and is the source of $\mathrm{O}_{2}\left({ }^{1} \Delta_{g}\right)$, both of which are involved in electron detachment reactions. Further, the ozone depletion is expected to be strongest during sunrise and sunset times (Verronen et al., 2005). With our combined ion and neutral chemistry model, we are able to account for the neutral atmospheric changes caused by the SPE.

During the sunset of 23 October, the proton fluxes stayed relatively constant, although at a highly elevated level when contrasted with quiet-time levels. At altitudes above $65 \mathrm{~km}$ the calculated ionization rates, based on GOES 

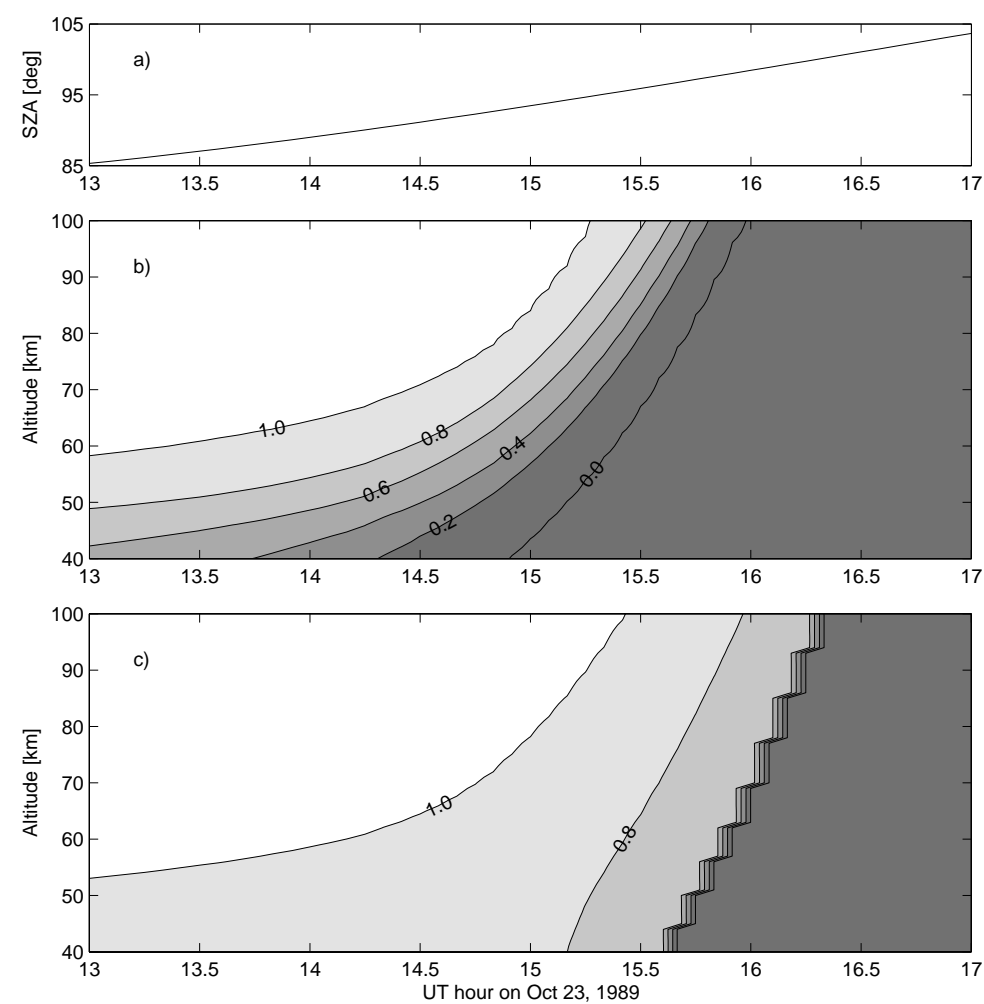

Fig. 2. (a) Solar zenith angles for the sunset of 23 October. (b) Calculated scaling factors for UV-dependent reaction rate coefficients. (c) Same as (b) but for VIS-dependent reactions. The same contour lines are shown in both (b) and (c), but for practical reasons only two of the lines are labelled in the bottom panel.

measurements, show a steady reduction by $5-15 \%$ between 12:00 and 18:00 UT. Therefore, the sunset transition under study was not significantly disturbed by sudden changes in the proton forcing.

In the SIC model, photodetachment is considered for $\mathrm{O}^{-}$, $\mathrm{O}_{2}^{-}, \mathrm{O}_{3}^{-}, \mathrm{OH}^{-}, \mathrm{CO}_{3}^{-}, \mathrm{NO}_{2}^{-}$, and $\mathrm{NO}_{3}^{-}$and photodissociation for $\mathrm{O}_{3}^{-}, \mathrm{O}_{4}^{-}, \mathrm{CO}_{3}^{-}, \mathrm{CO}_{3}^{-}\left(\mathrm{H}_{2} \mathrm{O}\right)$, and $\mathrm{CO}_{4}^{-}$. The photodissociation of $\mathrm{CO}_{3}^{-}$(and $\mathrm{CO}_{3}^{-}\left(\mathrm{H}_{2} \mathrm{O}\right)$ ) is important for twilight transitions because it releases $\mathrm{O}^{-}$, which then, in turn, rapidly releases an electron (Peterson, 1976). In addition to photon-driven reactions, there are a number of two-body reactions which release an electron, involving $\mathrm{O}^{-}, \mathrm{O}_{2}^{-}, \mathrm{O}_{3}^{-}$, $\mathrm{OH}^{-}$, and $\mathrm{Cl}^{-}$. These reactions and their rate coefficients are given by Turunen et al. (1996), except the photodissociation of $\mathrm{CO}_{3}^{-}\left(\mathrm{H}_{2} \mathrm{O}\right)$ which comes from Peterson (1976). For the photodetachment and photodissociation reactions the rate coefficients are given in "full-light" conditions; in the model we scale them based on the illumination level, in a manner similar to del Pozo et al. (1999). The scaled coefficient $k_{s}$ is calculated from the "full-light" coefficient $k$ as

$k_{s}=\frac{F}{F_{0}} k$,

where $F$ is the wavelength-integrated solar flux at a certain altitude at a certain time. $F_{0}$ is a reference flux pre-calculated for the same altitude but for solar zenith angle of $45^{\circ}$. For $\mathrm{NO}_{3}^{-}$photodetachment the fluxes are integrated from 99 to
$318 \mathrm{~nm}$ (Reid, 1987), while for photodetachment and photodissociation of other ions the integration is done from 99 to $422 \mathrm{~nm}$. Figure 2 shows the calculated UV-dependent $(<318 \mathrm{~nm})$ and VIS-dependent $(<422 \mathrm{~nm})$ scaling factors $\left(\frac{F}{F_{0}}\right)$, as well as the solar zenith angles for the sunset of 23 October. The UV and VIS wavelengths are attenuated differently, especially at high solar zenith angles. UV attenuation is strong and during sunset UV fluxes gradually reduce to zero well before the ray interception by the solid Earth occurs. In contrast, VIS radiation is only partially attenuated before the interception, when it is practically "switched off".

Solar flux values at each altitude are determined using the well-known Beer-Lambert absorption law, with the daily above-atmosphere fluxes provided by the SOLAR2000 model, version 2.23 (Tobiska et al., 2000). Calculation of optical depth is required, and for high zenith angles it is necessary to take into account the spherical geometry of the atmosphere. In our model, the optical depth calculation follows a procedure described by Rees $(1989$, p. 12-13). Note that in the calculations we do not take into account refraction, the effect of which is negligible for all ray paths, except maybe those with a tangent point very close to the Earth's surface (Reid, 1987). The main absorbing gases are molecular oxygen and ozone. The MSISE90 model provides $\mathrm{O}_{2}$ concentration profiles down to the ground level (Hedin, 1991), while for $\mathrm{O}_{3}$ we use the model results, so that the optical depth calculation takes into account the changes in ozone due to the 

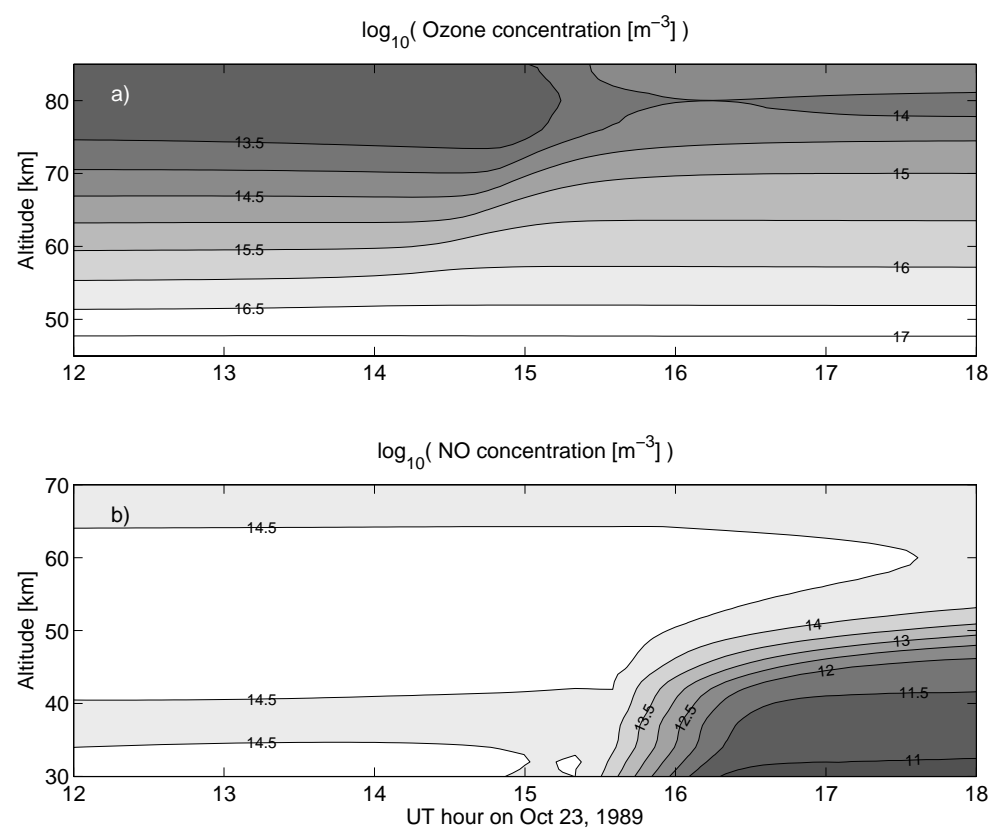

Fig. 3. Modelled variation of (a) ozone and (b) nitric oxide concentrations during the sunset of 23 October 1989.

proton precipitation, as well as the normal diurnal variation which is substantial in the upper stratosphere and above (see Fig. 3a). However, ozone values below the lower altitude limit of the model at $20 \mathrm{~km}$ are also needed because for solar zenith angles larger than $90^{\circ}$ the ray path passes through these lower altitudes. In the model we use values from Shimazaki (1984) and Brasseur and Solomon (1986) for these altitudes, assuming a fixed ozone profile throughout the modelling. This assumption is reasonable because 1) at altitudes below about $40 \mathrm{~km}$ there is no diurnal variation of ozone and 2) even for large SPEs the effects are typically not significant below $\sim 30 \mathrm{~km}$.

\section{Measurements}

\subsection{Electron density from EISCAT VHF incoherent scatter radar}

Incoherent scatter radars can provide altitude profiles of ionospheric quantities, such as electron density. The technique includes transmitting a power pulse, which is then scattered in the ionosphere, so that the returned power can be measured. Several experiment modes were used during the SPEs of 1989; these are described in, for example, Collis and Rietveld (1990).

On 23 October the VHF radar was operated in the special D-region mode "GEN-11" (Turunen, 1986). The antenna was tilted $45^{\circ}$ towards north, so that the lower altitude limit within the radar range was further lowered from $70 \mathrm{~km}$ to $50 \mathrm{~km}$. However, due to instrumental limitations the true lower limit of measurements was $54 \mathrm{~km}$ (Collis and Rietveld, 1990). The quiet-time electron densities in the lower
D-region, below $70 \mathrm{~km}$, are of the order of $10^{7}-10^{8} \mathrm{~m}^{-3}$ (see, e.g. Hargreaves, 1992, p. 231). For these kinds of small values the EISCAT signal-to-noise ratio is too low for measurements to be practical (Turunen, 1993). However, in this case the SPE-elevated ionization levels allowed for observations reaching stratopause altitudes.

The radar in Troms $\emptyset$, Norway $\left(69.59^{\circ} \mathrm{N}, 19.23^{\circ} \mathrm{E}\right)$ was operated from 12:00 UT until 18:00 UT, measuring the sunset conditions in the D-region. The altitude resolution of the measurements was $\approx 0.75 \mathrm{~km}$ for the tilted antenna $(\approx 1.05 \mathrm{~km}$ for a vertical $)$ and the basic time resolution was $10 \mathrm{~s}$. Before the analysis, the data were post-integrated over 5 minutes and interpolated to $1-\mathrm{km}$ grid. The error of the post-integrated data depends on the received power, i.e. for lower electron densities the uncertainty is larger, but is typically better than $10 \%$ (Collis and Rietveld, 1990).

\subsection{Cosmic radio noise absorption from Kilpisjärvi riome- ter}

Riometers measure ionospheric absorption of cosmic radio noise, typically at frequencies of $20-60 \mathrm{MHz}$. Cosmic radio noise is of galactic origin and is considered to be constant over long periods of time, so that any changes in the signal observed on the ground are due to changes in ionospheric absorption. The absorption depends upon electron-neutral collision frequency, which, in turn, depends upon electron density and temperature. Typically, most of the absorption occurs in D-region altitudes, i.e. below $90 \mathrm{~km}$. Riometers are relatively cheap, easy to operate, and can continuously measure the integrated ionization levels of the overhead ionosphere. Interpretation of measurements includes determination of a quiet-day curve (QDC), which is then subtracted 

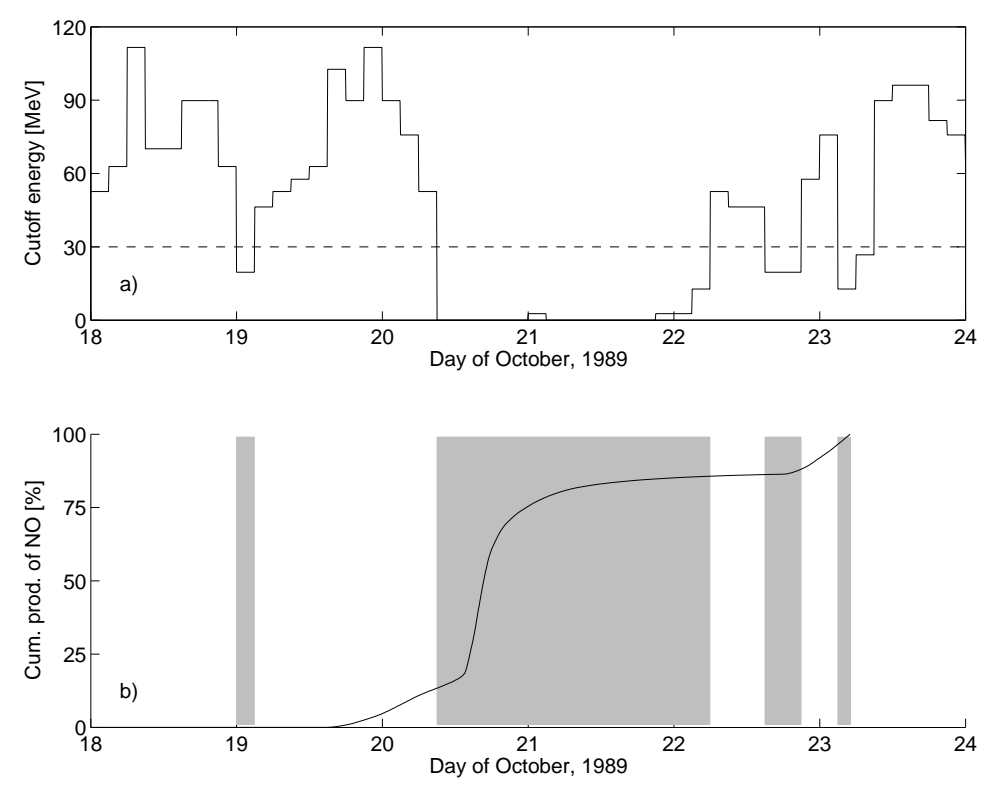

Fig. 4. (a) Calculated magnetic rigidity cutoff energies for the rocket measurement location. (b) Cumulative production of $\mathrm{NO}$ at $50 \mathrm{~km}$ from 18 October to 23 October 05:00 UT (model results, no cutoff applied). The shaded areas indicate the times of NO production when taking into account the variation with time of the cutoff energy.

from measurements, so that the final absorption data by riometers are relative in nature. For a description of riometer techniques and measurements, see, e.g. Ranta et al. (1983). In this study we have used measurements of the Kilpisjärvi riometer $\left(69.05^{\circ} \mathrm{N}, 20.78^{\circ} \mathrm{E}, f=30 \mathrm{MHz}\right)$, located in northern Finland, about $85 \mathrm{~km}$ east of the location of the EISCAT radar.

\subsection{Nitric oxide from a Southern Hemispheric rocket flight}

There is not much information available on polar nitric oxide during the October 1989 SPE. The only measurements we are aware of are those by Zadorozhny et al. (1994), who flew a M-100B meteorological rocket on 23 October, at 05:00 UT, in the Southern Hemisphere at $55.62^{\circ} \mathrm{S}, 50.18^{\circ} \mathrm{E}$. The time of the measurement is well suited for comparison with our modelling, because it is more than two days after the peak forcing by protons and only $7 \mathrm{~h}$ before the beginning of the EISCAT electron density measurements. On the other hand, the illumination conditions are quite different from those of our modelling location in the Northern Hemisphere. The solar zenith angle for the time and location of the rocket flight is about $55^{\circ}$ while at the modelling location the smallest zenith angle is about $81^{\circ}$ at 10:25 UT. Although $\mathrm{NO}_{\mathrm{x}}$ has a relatively long photochemical lifetime, there is a strong diurnal variation between $\mathrm{NO}$ and $\mathrm{NO}_{2}$ in the lower mesosphere and stratosphere. During daytime a photochemical equilibrium exists but at night most of $\mathrm{NO}$ is converted to $\mathrm{NO}_{2}$ through a reaction with $\mathrm{O}_{3}$ (see Fig. 3b). For this reason, we choose the modelled 10:25 UT NO profile to be compared with the rocket measurement. In addition to different illumination conditions, meteorological conditions are differ- ent in the Southern Hemisphere than in the Northern. In the south, the polar vortex is breaking up, while in the north it is forming. This might lead to important differences in NO because of the possible accumulation of NO inside the southern vortex during the preceding winter months, due to absence of photodissociation and vertical transport (see, e.g. Siskind et al., 1997). Nevertheless, we pursue the comparison because the high production of $\mathrm{NO}_{\mathrm{x}}$, due to the SPE, is likely to have a significant impact on the NO levels at the D-region altitudes. An indication of this is given by another, pre-SPE rocket measurent by Zadorozhny et al. (1994) on 12 October $\left(57.08^{\circ} \mathrm{S}, 45.04^{\circ} \mathrm{E}\right)$, which clearly shows lower values of NO than the observation during the SPE on 23 October, especially in the lower mesosphere and upper stratosphere. In Sect. 4.1 we will show that the observed and modelled, during-SPE altitude profiles have a very similar shape, which is another indication of the dominant role of SPE-produced NO.

In the stratosphere and lower mesosphere the photochemical lifetime of $\mathrm{NO}_{\mathrm{x}}$, which is determined by photodissociation of $\mathrm{NO}$, is relatively long compared to the duration of the SPE (Zadorozhny et al., 1994). Therefore, most of the $\mathrm{NO}_{\mathrm{x}}$ produced during the SPE is still present on 23 October. In the upper mesosphere and lower thermosphere, the lifetime of $\mathrm{NO}_{\mathrm{x}}$ is of the order of 1 day in solar illuminated conditions (Barth et al., 2001), so that a part of the SPE-produced $\mathrm{NO}_{\mathrm{x}}$ will have been destroyed before the rocket measurement was made. In summary, the measured and modelled NO profiles should be most comparable in the lower mesosphere, while at higher altitudes the different illumination conditions between the two locations may have significantly different influences on the $\mathrm{NO}_{\mathrm{x}}$ produced during the SPE. 


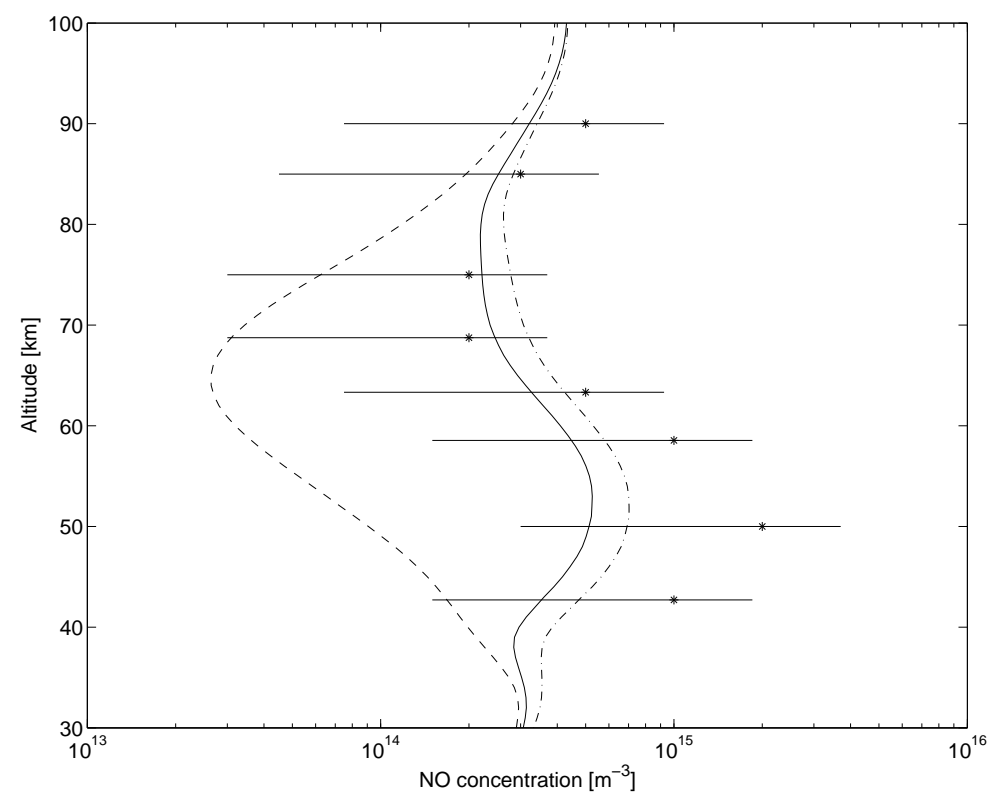

Fig. 5. NO concentration profiles. Modelling results for 18 October (dashed line) and 23 (solid line) at 10:25 UT are shown, as well as rocket data (stars) from Zadorozhny et al. (1994), including the $85 \%$ error margins. The dash-dot line shows the model result for 23 October when applying a higher production of NO by secondary electrons.

Modelling results by Jackman et al. (1995) indicate that the absolute increase of $\mathrm{NO}_{\mathrm{y}}\left(=\mathrm{N}+\mathrm{NO}+\mathrm{NO}_{2}\right.$ in the mesosphere) during the October 1989 SPE was essentially the same in both hemispheres. However, because our modelling location and the location of the rocket flight have markedly different magnetic latitudes, they should experience different proton forcing due to differences in magnetic rigidity cutoff, which determines the minimum energy required for a proton to reach a certain geographic location (see, e.g. Hargreaves, 1992, p. 355). To check if this was the case, we calculated the rigidity cutoff energies at the two locations for the duration of the SPE using a method which depends upon the measured $K_{p}$ magnetic index (see Rodger et al., 2006, for a description of the method). Our modelling location is well within the magnetic polar cap so that there is effectively no cutoff at any time. At the location of the rocket flight, which is near the edge of the magnetic polar cap, the cutoff energies, shown in the upper panel of Fig. 4, are high for most of the event and display large variations. However, it turns out that the high cutoffs have a relatively small effect on the total NO production in this case (see Sect. 4.1 for a discussion).

\section{Results and discussion}

\subsection{Nitric oxide}

Figure 5 compares the modelled and rocket-measured NO profiles, which are very similar in shape. The maximum of NO is at $45-60 \mathrm{~km}$, a minimum is at $70-80 \mathrm{~km}$, and above $80 \mathrm{~km}$ the concentration again increases. The modelled concentrations are within the error margins of the measure- ments at all altitudes and the agreement between the measured and modelled NO values is very good at the altitudes studied by riometers and EISCAT radar, i.e. between 60 and $80 \mathrm{~km}$. However, the difference in concentration is quite substantial around $50 \mathrm{~km}$, where the measured amount of $\mathrm{NO}$ $\left(\approx 2 \times 10^{15} \mathrm{~m}^{-3}\right)$ is four times higher than the modelled value $\left(\approx 5 \times 10^{14} \mathrm{~m}^{-3}\right)$. We discuss the possible reasons for this difference below.

The main part of the energy input and NO production by protons occurs between 40 and $80 \mathrm{~km}$, where the modelling result for NO is independent of its initial amount (assuming that the initial values before the SPE are lower than those measured after the onset of the SPE). Therefore, if we assume that there is no additional production of NO, the reason for the lower model values might be in the assumptions behind the SIC-modelled production of NO by protons. It should be noted that above $80 \mathrm{~km}$, where the proton forcing has a smaller effect, a better agreement with the measurements was obtained by using a downward NO flux of $4 \times 10^{13} \mathrm{~m}^{-2} \mathrm{~s}^{-1}$ at the upper boundary of the model $(120 \mathrm{~km})$ during both initialisation and modelling.

Assuming that the majority of the NO produced by the SPE was not destroyed before 23 October, Zadorozhny et al. (1994) estimated the concentration of NO at $50-\mathrm{km}$ altitude from

$[\mathrm{NO}]=C \int P_{i} d t$

where $P_{i}$ is the calculated ionization rate and $C$ is a constant varying between 1.2 and 1.6 (see, e.g. Porter et al., 1976; Rusch et al., 1981). Integrating from the beginning of the SPE until the rocket flight time, they calculated [NO] to 


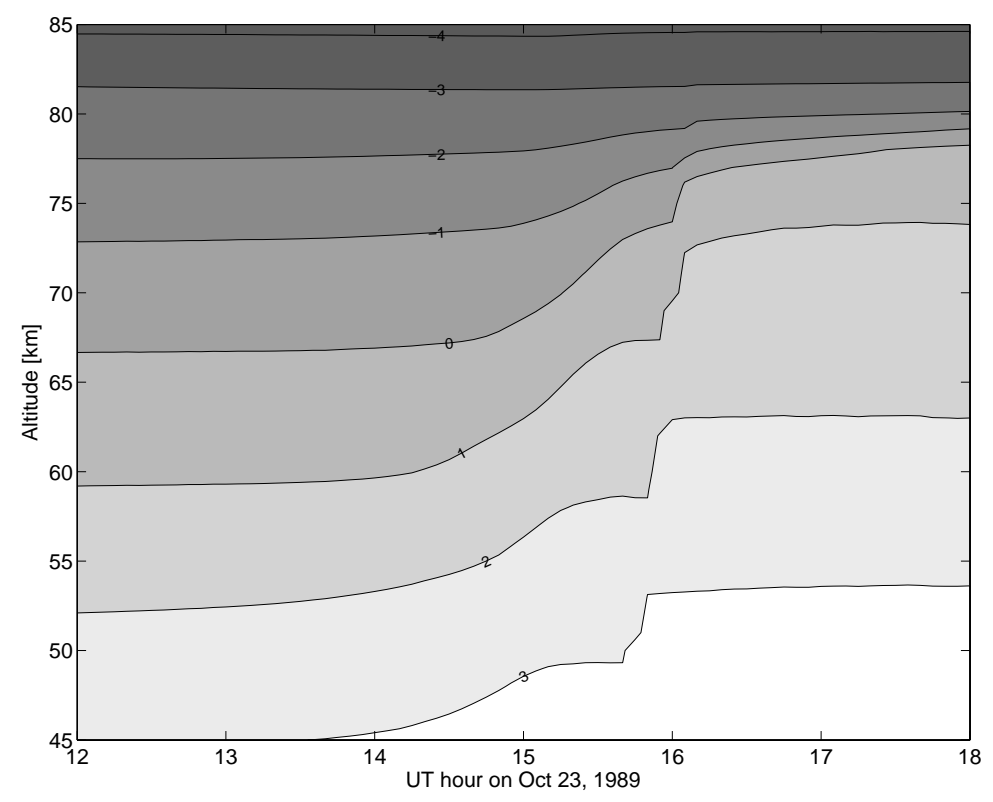

Fig. 6. Modelled negative ion to electron ratio, $\log _{10}\left(\frac{n_{i}^{-}}{n_{e}^{-}}\right)$, during the sunset of 23 October. The sharp changes seen around 16:00 UT indicate the times of the Earth's shadow covering corresponding altitudes.

be $1.1-1.4 \times 10^{15} \mathrm{~m}^{-3}$ without taking into account the effect of magnetic cutoff. Using the same approach for our modelling results, we calculated [NO] to be $6.7-9.3 \times 10^{14} \mathrm{~m}^{-3}$, which is about $35 \%$ lower, partly due to different neutral atmospheres and ionization rate calculation routines used. The proton energy required for reaching $50-\mathrm{km}$ altitude is about $30 \mathrm{MeV}$. Integrating the NO production only at times when the cutoff energy (shown in the upper panel of Fig. 4) is smaller than $30 \mathrm{MeV}$ results in about a $20 \%$ reduction in the final concentration at 05:00 UT. The applied cutoff has a moderate effect because, as shown in the bottom panel of Fig. 4, most of the NO production occurs on 20 October, when the proton flux was highest and the cutoff was at its lowest. Therefore, in the lower mesosphere the total NO production by the SPE on the modelling location should be comparable to that at the rocket flight location.

The SIC equivalent of $C$ (in Eq. 4) can be estimated from the model results by considering the different pathways leading from ionization to $\mathrm{NO}_{\mathrm{x}}$ production through dissociation of $\mathrm{N}_{2}$ by protons and secondary electrons, as well as a number ion chemical reactions. By dividing the $\mathrm{NO}_{\mathrm{x}}$ production rate by the ionization rate, the constant $C$ is found to be about 1.15 at $50 \mathrm{~km}$, i.e. in the lower limit of its theoretical range. An adjustable parameter in the model is the production of atomic nitrogen by secondary electrons, which is set to 0.8 times the ionization rate, equal to the lower limit given by Rusch et al. (1981). Figure 5 shows that by using the upper limit of this parameter, 1.21 (i.e. $C \approx 1.56$ ), the resulting amount of $\mathrm{NO}$ at $50 \mathrm{~km}$ is about $7 \times 10^{14} \mathrm{~m}^{-3}$, which is still almost three times lower than the measured value.

Ionization leads to atomic nitrogen production first, and here the branching between $\mathrm{N}\left({ }^{2} \mathrm{D}\right)$ and $\mathrm{N}\left({ }^{4} \mathrm{~S}\right)$ states is im- portant because the former produces NO while the latter destroys it (Brasseur and Solomon, 1986, p. 267). Zipf et al. (1980) have reported this branching to be close to 0.54 , favouring $\mathrm{N}\left({ }^{2} \mathrm{D}\right)$, but there is some uncertainty and this ratio is commonly used as a fitting parameter in models. In our model we use a value of 0.6. As a sensitivity test, we increased the ratio to 0.75 and repeated the whole SPE modelling. The results (not shown) indicate that at $50 \mathrm{~km}$ the amount of NO is quite insensitive to the change while at 65$80 \mathrm{~km}$ the NO values clearly exceeded the measured ones.

Zadorozhny et al. (1994) mention production by relativistic electron precipitation as a possible reason for the high amounts of NO measured at $50 \mathrm{~km}$. Since the uncertainties in the modelled SPE-driven production of NO are not able to fully explain the difference between modelling and the rocket measurements, an additional production source seems quite probable, especially if taking into account that the $\mathrm{NO}_{\mathrm{x}}$ $\left(=\mathrm{NO}+\mathrm{NO}_{2}\right)$ production of the SIC model has been validated during another SPE by the GOMOS instrument aboard the Envisat satellite (Verronen et al., 2005).

\subsection{Negative ion concentrations}

In D-region research, it is usual to show the negative ion to electron ratio, $\lambda$. A graph of this parameter, based on the model results, is presented as a function of time and altitude in Fig. 6 for the sunset hours of 23 October. It clearly demonstrates the transition of negative charge from ions to electrons during the sunset. Before the sunset, the transition altitude, where negative ion and electron concentrations are equal, is at $\approx 67 \mathrm{~km}$, while after the sunset it is at $\approx 78 \mathrm{~km}$. 

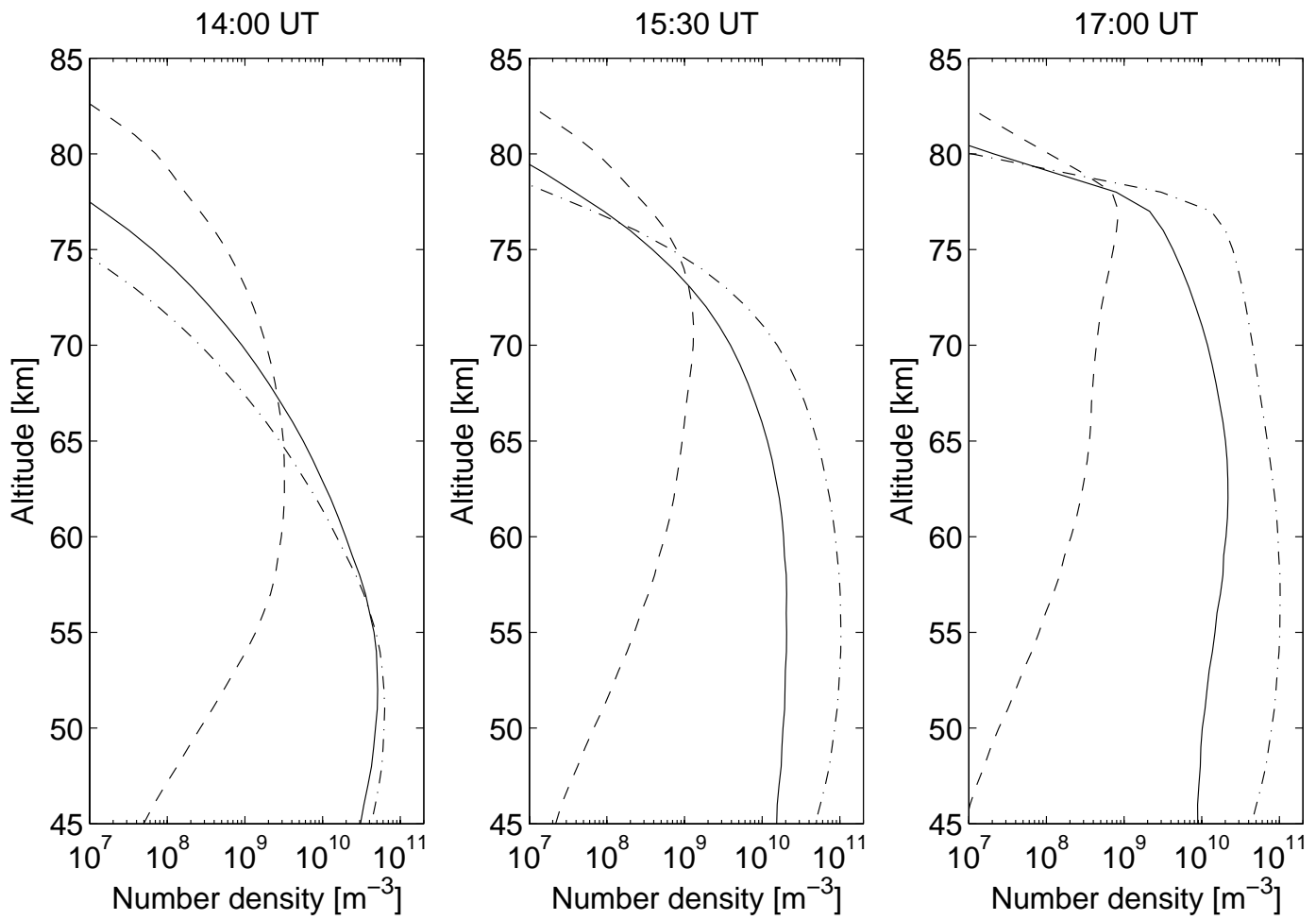

Fig. 7. Modelled density profiles of the main negative ions before, during, and after the sunset of 23 October. Dashed line, solid line, and dash-dot line indicate $\mathrm{O}_{2}^{-}, \mathrm{CO}_{3}^{-}$, and $\mathrm{NO}_{3}^{-}$, respectively.

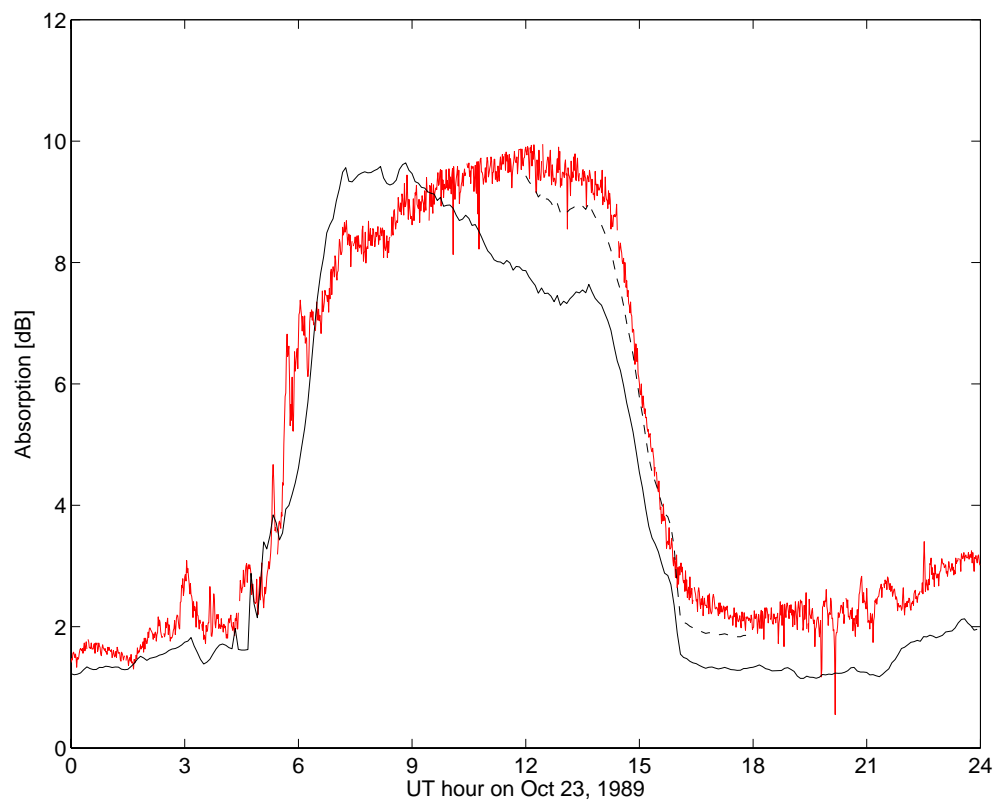

Fig. 8. Cosmic radio noise absorption as calculated from the model results (solid black line) and as measured by the Kilpisjärvi 30-MHz riometer (solid red line) $85 \mathrm{~km}$ east of the modelling location. Also shown is the calculated absorption when taking into account the estimated constant relativistic electron precipitation (dashed black line).

Figure 7 shows the model density profiles of the main negative ions before, during, and after the sunset transition. The main daytime ions in the lower mesosphere are $\mathrm{NO}_{3}^{-}$and $\mathrm{CO}_{3}^{-}$. Around $65 \mathrm{~km}$ these two are more or less equal with
$\mathrm{O}_{2}^{-}$which is the main ion at higher altitudes. There is also a multitude of other ions (including cluster ions) present, especially at lower altitudes, but with smaller concentrations. During the sunset a clear change in the ion composition 

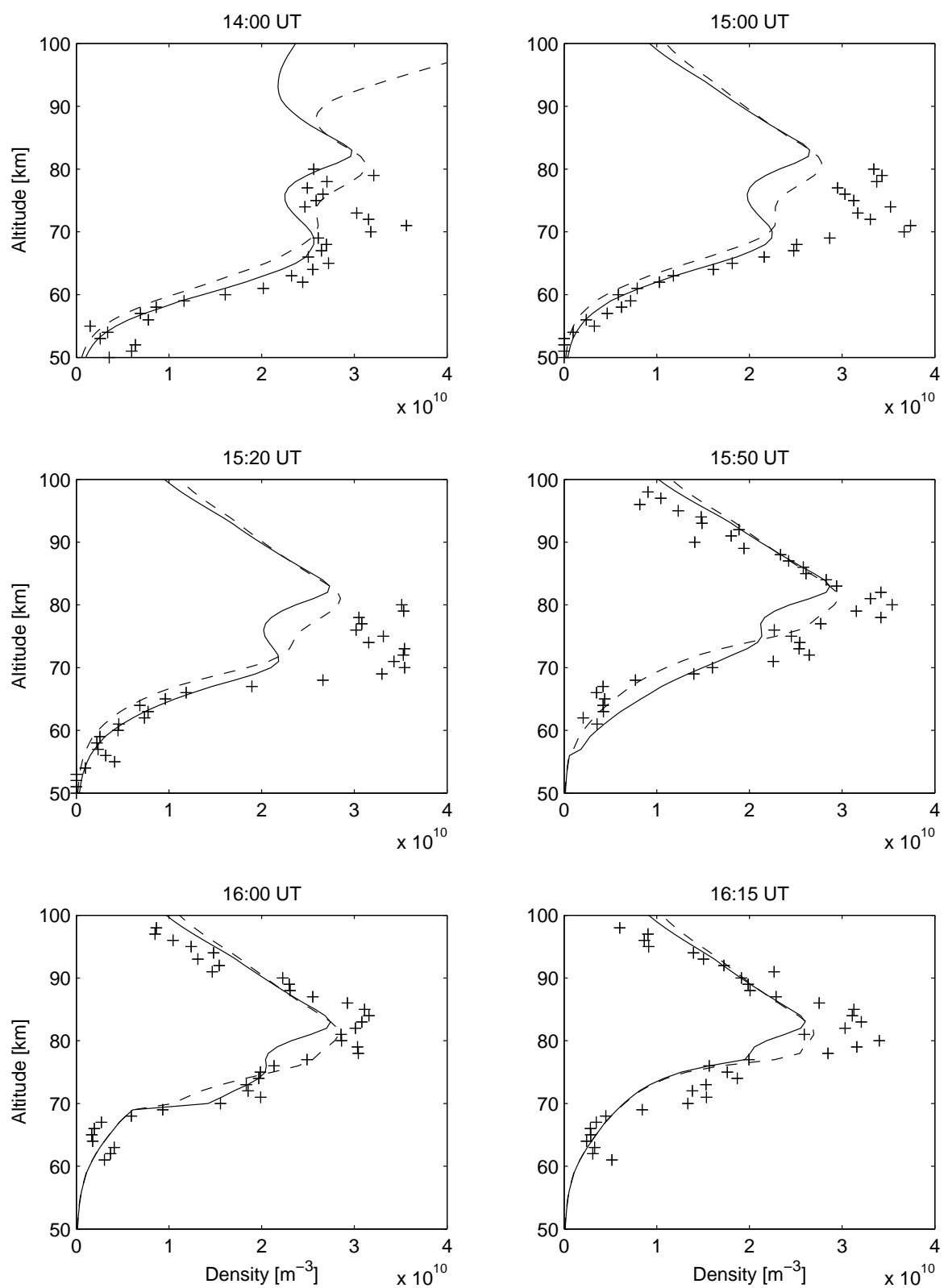

Fig. 9. Raw electron density profiles for selected times before, during, and after the sunset of 23 October. EISCAT measurements (+), as well as modelling results with model-determined NO (solid line) and with manually increased NO (dashed line), are shown.

occurs, which is related to the negative charge transition. $\mathrm{NO}_{3}^{-}$increases at all altitudes due to a reduction in its photodetachment. Also photodissociation of $\mathrm{CO}_{3}^{-}$decreases, at a later time, and its concentration increases at altitudes above $60 \mathrm{~km}$. $\mathrm{O}_{2}^{-}$decreases at altitudes below $70 \mathrm{~km}$, while $\mathrm{NO}_{3}^{-}$ and $\mathrm{CO}_{3}^{-}$, for which the main loss processes are the detachment/dissociation reactions, hold a larger and larger portion of the negative charge as the sunset advances. After sunset, when a nighttime balance is reached, $\mathrm{NO}_{3}^{-}$is clearly the main ion.

\subsection{Cosmic radio noise absorption}

Each run of the SIC model is based on a neutral background atmosphere given by the MSISE90 model and provides concentration profiles of neutral and ionic species. Cosmic radio noise absorption can be estimated from the modelling results by following Banks and Kockarts (1973, Part A, p. 194) and calculating the electron collision frequencies of $\mathrm{N}_{2}, \mathrm{O}_{2}$, and $\mathrm{He}$ from MSIS and of $\mathrm{O}$ and $\mathrm{H}$ from SIC, using the neutral temperature profile of MSIS, which we can assume to be equal to the electron temperature below $100 \mathrm{~km}$. Electron density is obtained from SIC by subtracting the sum of negative ion concentrations from the sum of positive ion 
concentrations. Finally, we use the method of Sen and Wyller (1960) to compute differential absorption $d L / d h$ and integrate with respect to height. This method takes the operational frequency of the riometer and assumes a dipole approximation for the geomagnetic field to obtain an electron gyrofrequency at the respective altitude and latitude.

Figure 8 shows the calculated absorption for 23 October compared to that measured by the Kilpisjärvi $30-\mathrm{MHz}$ riometer (located $85 \mathrm{~km}$ East of the modelling location), both of which show two distinct levels, $1-3 \mathrm{~dB}$ at night and $7-$ $10 \mathrm{~dB}$ during day. The daytime behaviours, from 07:00 to 14:00 UT (10:25 UT corresponds to local time noon), between the modelled and observed absorptions, differ significantly. The riometer shows a gradual increase between sunrise until the beginning of sunset, while calculated values follow the proton forcing, peaking at 07:00-09:00 UT and then gradually decrease until reaching a lower level at about 13:00 UT. The calculated absorption values are clearly lower than those measured at daytime (after 10:00 UT), as well as during and after the sunset. However, the sunset behaviour is well modelled, in time scale as well as in steepness of the transition.

At nighttime, when the D-region electron density is low, the contribution of upper altitudes can be important to total absorption, especially if auroral precipitation occurs. From EISCAT measurements (CP2 mode, from 18:00 UT onwards, not shown) it is evident that there was auroral electron precipitation after sunset, resulting in significantly higher electron density values at altitudes above $90 \mathrm{~km}$ compared to our modelling. By replacing the modelled densities with the measured ones and then repeating the absorption calculation from 18:00 to 24:00 UT, the resulting absorptions were clearly closer to those measured by the riometer. Therefore, a part of the after-sunset difference between the measured and modelled absorption can be explained by auroral electron precipitation. At daytime, the majority of the absorption comes from the D-region altitudes, such that typical auroral electron precipitation, if present, could explain only a small portion of the difference. However, in the following sections we will show that high-energy electron precipitation is a possible cause for the daytime differences.

\subsection{Electron densities}

For comparison, the modelled electron densities were converted to raw electron densities $N_{e}^{\text {raw }}$. The backscattered power of EISCAT radar is a direct measure of $N_{e}^{\text {raw }}$, which, on the other hand, is a function of the electron density and the total concentration of negative ions (see, e.g. del Pozo et al., 1999, and references therein for more details on the conversion).

Electron density profiles for selected times during the sunset are shown in Fig. 9. The shapes of the measured profiles vary significantly during sunset at altitudes below $80 \mathrm{~km}$. These variations are well represented by the model. For the profiles of 14:00 UT and from 15:50 UT on, the magnitudes agree within the EISCAT 10\% statistical uncertainty mar-
Table 1. Most important electron-detachment reactions from the SIC model. Sources of the rate coefficients are listed in Turunen et al. (1996). Units are $\mathrm{m}^{3} \mathrm{~s}^{-1}$ for $\mathrm{R} 1-\mathrm{R} 3$ and $\mathrm{s}^{-1}$ for the other reactions.

\begin{tabular}{llllr}
\hline$\#$ & Reaction & & & Rate coefficient \\
\hline $\mathrm{R} 1$ & $\mathrm{O}^{-}+\mathrm{M}$ & $\rightarrow$ & $\mathrm{O}+\mathrm{M}+\mathrm{e}$ & $<10^{-18}$ \\
$\mathrm{R} 2$ & $\mathrm{O}_{2}^{-}+\mathrm{O}_{2}\left({ }^{1} \Delta_{g}\right)$ & $\rightarrow$ & $2 \mathrm{O}_{2}+\mathrm{e}$ & $2.0 \times 10^{-16}$ \\
$\mathrm{R} 3$ & $\mathrm{O}_{2}^{-}+\mathrm{O}$ & $\rightarrow$ & $\mathrm{O}_{3}+\mathrm{e}$ & $1.5 \times 10^{-16}$ \\
$\mathrm{R} 4$ & $\mathrm{O}_{2}^{-}+h v(<2695 \mathrm{~nm})$ & $\rightarrow$ & $\mathrm{O}_{2}+\mathrm{e}$ & $3.8 \times 10^{-1}$ \\
$\mathrm{R} 5$ & $\mathrm{NO}_{3}^{-}+h v(<318 \mathrm{~nm})$ & $\rightarrow$ & $\mathrm{NO}_{3}+\mathrm{e}$ & $5.2 \times 10^{-2}$ \\
$\mathrm{R} 6$ & $\mathrm{CO}_{3}^{-}+h v(<428 \mathrm{~nm})$ & $\rightarrow$ & $\mathrm{CO}_{3}+\mathrm{e}$ & $2.2 \times 10^{-12}$ \\
\hline
\end{tabular}

gins at most altitudes. Most significant differences, which are clearly larger than the 10\% margin, are in the 15:00 UT and 15:20 UT profiles at altitudes above $65 \mathrm{~km}$. Since the negative charge transition during the sunset should result in decreasing rather than increasing electron density, a possible reason for the observed higher densities is an additional ionization source.

Considering the temporal behaviour, Fig. 10 shows the sunset electron densities for altitudes of 65,72 , and $80 \mathrm{~km}$. At $80 \mathrm{~km}$ there is no clear transition in either the measurements or in the modelling. This is expected because the electrons are dominant over negative ions at this altitude. The modelled density decreases after sunset, partly due to the gradual decrease in proton forcing, while the measured density stays more or less at the same level. At lower altitudes there are clear transitions, which begin at about 15:30 and 14:30 UT, at 72 and $65 \mathrm{~km}$, respectively. At $65 \mathrm{~km}$, the change is gradual until 16:00 UT, when there is a "drop off", i.e. a sudden decrease of electron density between 15:55 and 16:00 UT, corresponding to the Earth's shadow covering this altitude. This drop off is also seen in the data, although not as pronounced. The initial gradual change and drop-off end constitute a two-step process, similar to what has been observed in sunrise conditions (Collis and Rietveld, 1990). This indicates that the transition is dependent on both the UV and VIS solar radiation. At $72 \mathrm{~km}$, the transition is steeper than at $65 \mathrm{~km}$. The drop off occurs 5 min later than at $65 \mathrm{~km}$ and is not visible in the data, although such a step could be hidden by the $10 \%$ uncertainty. The measured values show a continuing transition until 16:30 UT, a feature that is within the uncertainty limits and is not confirmed by the model. Despite the differences in the magnitudes of electron density, the comparison shows that the model is able to represent the sunset transition reasonably well.

The model results indicate that the sunset transition of negative charge is a combination of VIS and UV sources. The main processes of negative ions releasing an electron are listed in Table 1 and the detachment rates of these reactions at 65 and $72 \mathrm{~km}$ are plotted in Figs. 11a-b. All these reactions are photon-driven either directly (R4-R6) or indirectly. R2 and R3 are controlled by UV-related changes in 

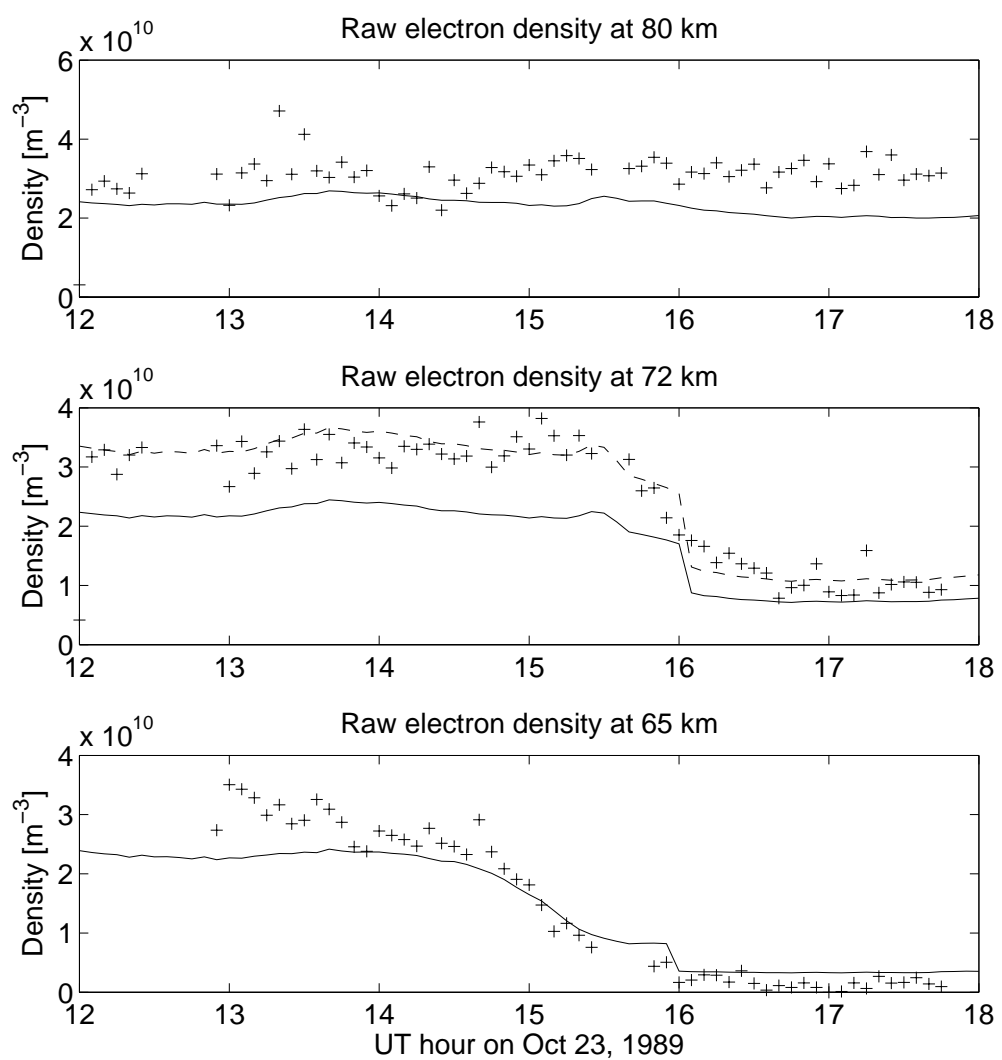

Fig. 10. Sunset behaviour of raw electron densities at selected altitudes from EISCAT measurements (+) and modelling (solid line). In the middle panel, the model values multiplied by 1.5 are shown (dashed line) to aid the comparison with the measured values.

atomic oxygen and $\mathrm{O}_{2}\left({ }^{1} \Delta_{g}\right)$, and the fast reaction $\mathrm{R} 1$ is also photon-driven because $\mathrm{O}^{-}$acts as an intermediate species between photodissociation of $\mathrm{CO}_{3}^{-}$and fast electron detachment (from $\mathrm{O}^{-}$). At $65 \mathrm{~km}$ the UV dependence is strong, with reactions $\mathrm{R} 2-\mathrm{R} 4$ contributing. It is worthwhile to note that the effect of the $\mathrm{O}_{2}\left({ }^{1} \Delta_{g}\right)$ change is larger than that of atomic oxygen change, and that the effect of $\mathrm{NO}_{3}^{-}$photodetachment is relatively small. Reactions R1, R4, and R6 contribute to the VIS dependence (displaying the drop off at 16:00 UT), with R1 being the most important of these. As noted earlier, the VIS dependence of $\mathrm{R} 1$ originates from $\mathrm{CO}_{3}^{-}$photodissociation. At $75 \mathrm{~km}$, the main VIS dependence comes from $\mathrm{R} 1$ and $\mathrm{R} 4$, i.e. $\mathrm{CO}_{3}^{-}$and $\mathrm{O}_{2}^{-}$. The UV dependence, which is relatively not as strong as at $65 \mathrm{~km}$, is, for the most part, due to changes in atomic oxygen and $\mathrm{O}_{2}\left({ }^{1} \Delta_{g}\right)$.

In the case of sunrise, the amount of NO determines the relative size of UV and VIS effects by controlling the balance between $\mathrm{NO}_{3}^{-}$and $\mathrm{CO}_{3}^{-}$(Reid, 1987). For our sunset case, we tested the sensitivity of our model by repeating the sunset calculation with a higher amount of NO. Starting at 11:00 UT, we manually increased the starting concentration by 5 times at all altitudes and then ran the model until 18:00 UT. The results (see Figs. 11c-d) show that, due to $\mathrm{NO}_{3}^{-}$holding a larger portion of the negative charge, 1) the UV effect is increased relative to the VIS effect at lower altitudes (where $\mathrm{NO}_{3}^{-}$and $\mathrm{CO}_{3}^{-}$are the main daytime ions), 2)
VIS-driven reaction rates R1, R4, and R6 show a more gradual decrease before the total "switch off", especially at higher altitudes, and 3) the photodetachment of $\mathrm{NO}_{3}^{-}$becomes relatively more important. The comparison with measured electron density profiles, shown in Fig. 9, improves, especially at altitudes $75-82 \mathrm{~km}$. At altitudes below 70 or $75 \mathrm{~km}$, depending on the UT time, the comparison generally becomes worse or at least does not improve. Except for the 14:00 UT case, where photoionization still operates on $\mathrm{NO}$ at higher altitudes, there is no significant effect on electron densities above $82 \mathrm{~km}$. Therefore, we could speculate that the original modelling underestimates the amount of NO between 70 and $85 \mathrm{~km}$. Although the increased concentrations of NO, e.g. $[\mathrm{NO}] \approx 10^{15} \mathrm{~m}^{-3}$ at $80 \mathrm{~km}$, exceed the measured values, this could perhaps be explained by the differences in illumination level, which, for the modelling location, is relatively low and favours the downward transport of NO produced at higher altitudes.

\subsection{High-energy electron flux}

The shape of the measured cosmic radio noise absorption, which does not follow the decreasing proton forcing but shows a gradual increase during the daylight hours (Fig. 8), could be explained by an additional ionization source. The same kind of behaviour is seen in measurements of some other riometer stations (not shown) in 

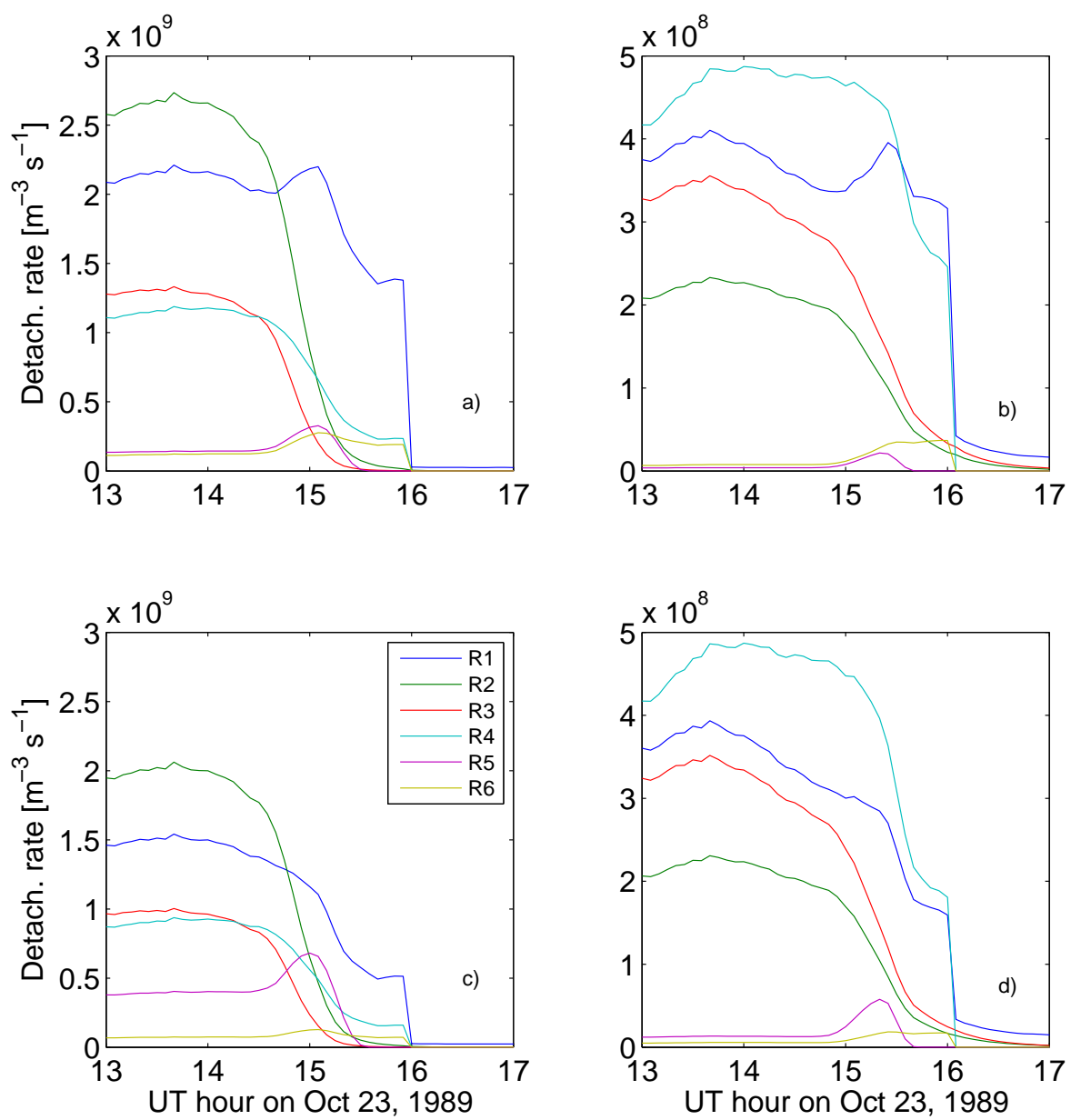

Fig. 11. Modelled rates of electron detachment from negative ions at (a) $65 \mathrm{~km}$ and (b) $72 \mathrm{~km}$. The legend, which is the same for all panels, identifies the reactions listed in Table 1. Panels (c) and (d) are as (a) and (b), respectively, but with manually increased NO.
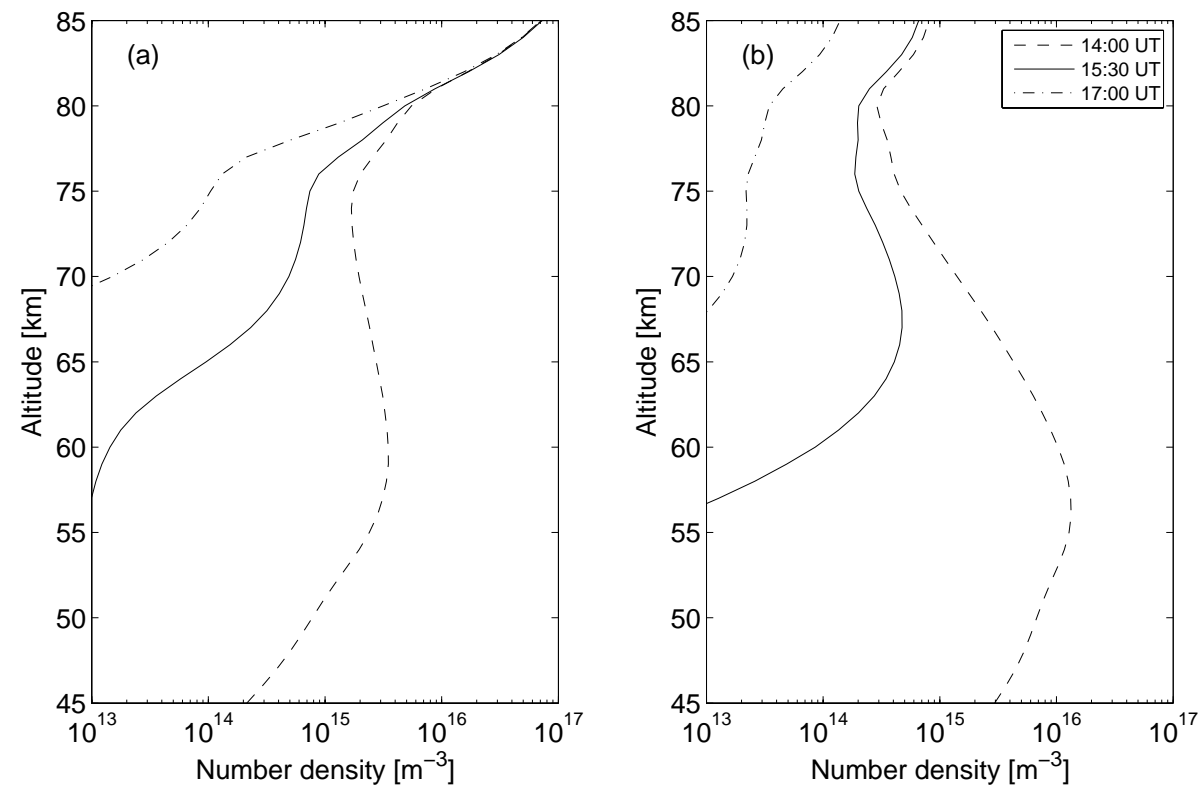

Fig. 12. Modelled concentration profiles of (a) atomic oxygen and (b) $\mathrm{O}_{2}\left({ }^{1} \Delta_{g}\right)$ before, during, and after the sunset of 23 October. 
the northern Fennoscandia area, especially that of Oulu $\left(65.05^{\circ} \mathrm{N}, 25.54^{\circ} \mathrm{E}\right)$, which shows a daytime increase by $\approx 25 \%$ from a.m. to p.m. hours. The additional source could be auroral electrons, but the discrepancy at $70-80 \mathrm{~km}$ between the measured and modelled electron densities (Fig. 9) requires electrons reaching relativistic energies.

By trial and error, we estimated the flux of monoenergetic beam of electrons required to increase the modelled electron densities to the measured level. Choosing the energy and flux, the resulting ionization rate was calculated following Rees (1989, p. 35-45) and using electron energy-range values from Goldberg et al. (1984) and Berger and Seltzer (1972). The calculated rate was then input in the model, together with the proton forcing, and the sunset modelling was rerun. We found that a combination of $650-\mathrm{keV}$ energy and $1.45 \times 10^{9} \mathrm{~m}^{-2} \mathrm{~s}^{-1}$ flux resulted in electron density levels quite close to the EISCAT measurements. This estimated flux is comparable to relatively high fluxes which have been measured during specific electron precipitation events by, e.g., the PET/SAMPEX instrument (Callis et al., 1996). Obviously, a monoenergetic and constant-flux beam is hardly a good representative of the real situation, but due to the lack of measurements we are limited to this approach, to provide a rough estimate.

By using the increased electron density profiles, the calculated radio noise absorption values, shown in Fig. 8, significantly increase, and show very good agreement with the riometer measurements. Therefore, it seems that an additional ionization source, most likely high-energy electrons, was present during the afternoon and sunset hours of 23 October.

\subsection{Spectral width of EISCAT measurements}

Del Pozo et al. (1999) studied the rapid change in incoherent scatter radar spectral width during the sunset of 23 October, roughly estimated the sunset change in the oxygen species, and concluded that change in atomic oxygen and to a lesser extent that of $\mathrm{O}_{2}\left({ }^{1} \Delta_{g}\right)$ could explain the observations. Our modelling results, shown in Fig. 12, agree with this conclusion, for the most part. Atomic oxygen and $\mathrm{O}_{2}\left({ }^{1} \Delta_{g}\right)$ show an order of magnitude (or greater) decrease at altitudes below $65 \mathrm{~km}$, from 14:00 UT to 15:30 UT, which is equal to the required reduction estimated by del Pozo et al. (1999). The spectral width is about twice as sensitive to the concentration to atomic oxygen than that of $\mathrm{O}_{2}\left({ }^{1} \Delta_{g}\right)$ at lower mesospheric altitudes (see Fig. 8 in del Pozo et al., 1999). Thus, above $65 \mathrm{~km}$, where the absolute reduction of $\mathrm{O}$ is equal to or higher than that of $\mathrm{O}_{2}\left({ }^{1} \Delta_{g}\right)$, the observed spectral width change is mostly due to the change in O. At lower altitudes, where the absolute change in $\mathrm{O}_{2}\left({ }^{1} \Delta_{g}\right)$ is clearly larger than that of atomic oxygen, the contributions of the two constituents may be more comparable.

\section{Conclusions}

A 1-D neutral and ion chemistry model has been used to interpret measurements of nitric oxide, cosmic radio noise absorption, and electron density made during the great proton storm of October 1989, in high ionization conditions. The model and the measurements are generally found to be in good agreement. Although there are still great uncertainties involved, e.g., in the photodetachment rates of ions, with the current knowledge we are able to model the D-region ionosphere with some success.

For the case considered, the sunset transition of negative charge displays dependency on both visible and ultraviolet solar radiation. The model results show that the UV response comes, for the most part, from atomic oxygen and $\mathrm{O}_{2}\left({ }^{1} \Delta_{g}\right)$ changes, with a smaller contribution from $\mathrm{NO}_{3}^{-}$photodetachment, while the VIS dependence is driven by reactions of $\mathrm{O}_{2}^{-}$and $\mathrm{CO}_{3}^{-}$. The relative magnitude of UV and VIS effects vary with altitude, with UV playing a larger role at lower altitudes. These transition characteristics are confirmed by both electron density and cosmic radio noise absorption measurements.

These sunset transition characteristics are not sensitive to the momentary ionization level, which determines the absolute amount of negative (and positive) charge but does not directly affect the balance between the ions. However, our modelling results are sensitive to the amount of NO which, because of its relatively long photochemical lifetime, depends upon the ionization history rather than the momentary ionization. It is therefore important for studies like the present one, to either model NO accurately or use measured values. However, this requirement can be quite difficult to fulfill because of the high variability of NO in the auroral regions, where the source is unpredictable and the illumination conditions vary significantly with season, and also due to spatial and temporal limitations of available data.

Both the cosmic radio noise and electron density measurements indicate a possible presence of an additional ionization source, the effect of which is comparable to the ionization caused by the SPE at altitudes $70-80 \mathrm{~km}$. By estimating a reasonable flux of high-energy electrons and including it in our model, the absolute magnitude of modelled values was found to be in excellent agreement with those measured by both instruments. It seems therefore likely that electron precipitation which reached relativistic energies occurred during the afternoon and sunset hours on 23 October.

According to our modelling results, sunset decreases in the amount of atomic oxygen and $\mathrm{O}_{2}\left({ }^{1} \Delta_{g}\right)$ are such that they can be used to explain the observed spectral width changes of incoherent scatter radar measurements, as suggested by del Pozo et al. (1999).

Acknowledgements. The work of P. T. Verronen was partially supported by the Academy of Finland through the ANTARES space research programme. EISCAT is an International Association supported by Finland (SA), France (CNRS), Germany (MPG), Japan (NIPR), Norway (NFR), Sweden (VR) and the United Kingdom (PPARC). GOES proton flux data were provided by the SPIDR 
online data repository. The authors thank N. Riipi and K. Sorri for updating Fig. 1. P. T. Verronen thanks J. Tamminen for usefull discussions.

Topical Editor M. Pinnock thanks A. M. Zadorozhny and another referee for their help in evaluating this paper.

\section{References}

Banks, P. M. and Kockarts, G.: Aeronomy, Academic Press, 1973.

Barth, C. A., Baker, D. N., and Mankoff, K. D., The northern auroral region as observed in nitric oxide, Geophys. Res. Lett., 28, 1463-1466, 2001.

Berger, M. J. and Seltzer, S. M.: Bremsstrahlung in the atmosphere, J. Atmos. Terr. Phys., 34, 85-108, 1972.

Brasseur, G. and Solomon, S.: Aeronomy of the Middle Atmosphere, D. Reidel Publishing Company, Dordrecht, 2nd edn., 1986.

Burns, C. J., Turunen, E., Matveinen, H., Ranta, H., and Hargreaves, J. K.: Chemical Modeling of the Quiet Summer D- and E-regions Using EISCAT Electron Density Profiles, J. Atmos. Terr. Phys., 53, 115-134, 1991.

Callis, L. B., Boughner, R. E., Baker, D. N., Mewaldt, R. A., Blake, J. B., Selesnick, R. S., Cummings, J. R., Natarajan, M., Mason, G. M., and Mazur, J. E.: Precipitation electrons: Evidence for effects on mesospheric odd nitrogen, Geophys. Res. Lett., 23, 1901-1904, 1996.

Clilverd, M. A., Rodger, C. J., Ulich, T., Seppälä, A., Turunen, E., Botman, A., and Thomson, N. R.: Modelling a large solar proton event in the southern polar cap, J. Geophys. Res., 110, A09307, 2005.

Collis, P. N. and Rietveld, M. T.: Mesospheric observations with the EISCAT UHF radar during polar cap absorption events: 1 . Electron densities and negative ions, Ann. Geophys., 8, 809-824, 1990.

del Pozo, C. F., Turunen, E., and Ulich, T.: Negative ions in the auroral mesosphere during a PCA event around sunset, Ann. Geophys., 17, 782-793, 1999,

\section{SRef-ID: 1432-0576/ag/1999-17-782.}

Goldberg, R. A., Jackman, C. H., Barcus, J. R., and Soraas, F.: Nighttime auroral energy deposition in the middle atmosphere, J. Geophys. Res., 89, 5581-5596, 1984.

Hargreaves, J. K.: The solar-terrestrial environment, Cambridge Atmospheric and Space Science Series, Cambridge University Press, Cambridge, UK, 1992.

Hedin, A. E.: Extension of the MSIS Thermospheric Model into the Middle and Lower Atmosphere, J. Geophys. Res., 96, 1159$1172,1991$.

Jackman, C. H., Cerniglia, M. C., Nielsen, J. E., Allen, D. J., Zawodny, J. M., McPeters, R. D., Douglass, A. R., Rosenfield, J. E., and Hood, R. B.: Two-dimensional and three-dimensional model simulations, measurements, and interpretation of the October 1989 solar proton events on the middle atmosphere, J. Geophys. Res., 100, 11 641-11660, 1995.

Peterson, J. R.: Sunlight photodestruction of $\mathrm{CO}_{3}^{-}$, its hydrate, and $\mathrm{O}_{3}^{-}$- The importance of photodissociation to the $\mathrm{D}$ region electron densities at sunrise, J. Geophys. Res., 81, 1433-1435, 1976.

Porter, H. S., Jackman, C. H., and Green, A. E. S.: Efficiencies for production of atomic nitrogen and oxygen by relativistic proton impact in air, J. Chem. Phys., 65, 154-167, 1976.

Ranta, H., Ranta, A., Rosenberg, T. J., and Detrick, D. L.: Autumn and winter anomalies in ionospheric absorption as measured by riometers, J. Atmos. Terr. Phys., 45, 193-202, 1983.

Rees, M. H.: Physics and chemistry of the upper atmosphere, Cambridge atmospheric and space science series, Cambridge University Press, Cambridge, UK, 1989.

Reid, G. C.: Radar observations of negative-ion photodetachment at sunrise in the auroral-zone mesosphere, Planet. Space Sci., 35, 27-37, 1987

Reid, G. C., Solomon, S., and Garcia, R. R.: Response of the middle atmosphere to the solar proton events of August-December, 1989, Geophys. Res. Lett., 18, 1019-1022, 1991.

Rietveld, M. T. and Collis, P. N.: Mesospheric observations with the EISCAT UHF radar during polar cap absorption events: 2. Spectral measurements, Ann. Geophys., 11, 797-808, 1993.

Rietveld, M. T., Turunen, E., Matveinen, H., Goncharov, N. P., and Pollari, P.: Artificial periodic irregularities in the auroral ionosphere, Ann. Geophys., 14, 1437-1453, 1996,

SRef-ID: 1432-0576/ag/1996-14-1437.

Rodger, C. J., Clilverd, M. A., Verronen, P. T., Ulich, T., Jarvis, M. J., and Turunen, E.: Dynamic geomagnetic rigidity cutoff variations during a solar proton event, J. Geophys. Res., in press, 2006.

Rusch, D. W., Gérard, J.-C., Solomon, S., Crutzen, P. J., and Reid, G. C.: The effect of particle precipitation events on the neutral and ion chemistry of the middle atmosphere - I. Odd nitrogen, Planet. Space Sci., 29, 767-774, 1981.

Sander, S. P., Friedl, R. R., Golden, D. M., Kurylo, M. J., Huie, R. E., Orkin, V. L., Moortgat, G. K., Ravishankara, A. R., Kolb, C. E., Molina, M. J., and Finlayson-Pitts, B. J.: Chemical Kinetics and Photochemical Data for Use in Stratospheric Modeling: Evaluation number 14, JPL Publication 02-25, Jet Propulsion Laboratory, California Institute of Technology, Pasadena, USA, 2003.

Sen, H. K. and Wyller, A. A.: On the generalization of the Appleton-Hartree magnetoionic formulas, J. Geophys. Res., 65, 3931-3950, 1960.

Shimazaki, T.: Minor Constituents in the Middle Atmosphere (Developments in Earth and Planetary Physics, No 6), D. Reidel Publishing Co., Dordrecht, Holland, 1984.

Siskind, D. E., Bacmeister, J. T., Summers, M. E., and Russell, J. M.: Two-dimensional Model Calculations of Nitric Oxide Transport in the Middle Atmosphere and Comparison with Halogen Occultation Experiment Data, J. Geophys. Res., 102, 3527 3545, 1997.

Solomon, S., Rusch, D. W., Gérard, J.-C., Reid, G. C., and Crutzen, P. J.: The effect of particle precipitation events on the neutral and ion chemistry of the middle atmosphere: II. Odd hydrogen, Planet. Space Sci., 8, 885-893, 1981

Thomas, R. J., Barth, C. A., Rottman, G. J., Rusch, D. W., Mount G. H., Lawrence, G. M., Sanders, R. W., Thomas, G. E., and Clemens, L. E.: Ozone density distribution in the mesosphere 150-90 km/ measured by the SME limb scanning near infrared spectrometer, Geophys. Res. Lett., 10, 245-248, 1983.

Tobiska, W. K., Woods, T., Eparvier, F., Viereck, R., Floyd, L. D. B., Rottman, G., and White, O. R.: The SOLAR2000 empirical solar irradiance model and forecast tool, J. Atmos. Terr. Phys., 62 , 1233-1250, 2000.

Turunen, E.: EISCAT incoherent scatter radar observations and model studies of day to twilight variations in the $\mathrm{D}$ region during the PCA event of August 1989, J. Atmos. Terr. Phys., 55, 767-781, 1993

Turunen, E., Matveinen, H., Tolvanen, J., and Ranta, H.: D-region ion chemistry model, in STEP Handbook of Ionospheric Mod- 
els, edited by: Schunk, R. W., SCOSTEP Secretariat, Boulder, Colorado, USA, 1-25,1996.

Turunen, T.: GEN-system, a new experimental philosophy for EISCAT radars, J. Atmos. Terr. Phys., 48, 777-785, 1986.

Ulich, T., Turunen, E., and Nygrén, T.: Effective Recombination Coefficient in the Lower Ionosphere During Bursts of Auroral Electrons, Adv. Space Res., 25, 47-50, 2000.

Verronen, P. T., Turunen, E., Ulich, T., and Kyrölä, E.: Modelling the effects of the October 1989 solar proton event on mesospheric odd nitrogen using a detailed ion and neutral chemistry model, Ann. Geophys., 20, 1967-1976, 2002,

SRef-ID: 1432-0576/ag/2002-20-1967.
Verronen, P. T., Seppälä, A., Clilverd, M. A., Rodger, C. J., Kyrölä, E., Enell, C.-F., Ulich, T., and Turunen, E.: Diurnal variation of ozone depletion during the October-November 2003 solar proton events, J. Geophys. Res., 110, A09S32, 2005.

Zadorozhny, A. M., Kikhtenko, V. N., Kokin, G. A., Tuchkov, G. A., Tyutin, A. A., Chizhov, A. F., and Shtirkov, O. V.: Middle atmosphere response to the solar proton events of October 1989 using the results of rocket measurements, J. Geophys. Res., 99, 21 059-21 069, 1994.

Zipf, E. C., Espy, P. J., and Boyle, C. F.: The Excitation and Collisional Deactivation of Metastable $\mathrm{N}\left({ }^{2} \mathrm{P}\right)$ Atoms in Auroras, J. Geophys. Res., 85, 687-694, 1980. 